\title{
IMPLEMENTASI PROGRAM KAMPUNG KELUARGA BERENCANA (KB) DI KABUPATEN KUNINGAN TAHUN 2018 (Studi Kuantitatif Dan Kualitatif)
}

\author{
Siti Nunung Nurjannah, Euis Susanti \\ Program Studi Kebidanan Sekolah Tinggi Ilmu Kesehatan Kuningan Garawangi \\ sitinunung.nurjannah@gmail.com
}

\begin{abstract}
Abstrak
Program Kampung KB merupakan salah satu program inovatif pemerintah yang strategis dalam memperkuat program Kependudukan Keluarga Berencana dan Pembangunan Keluarga dengan mempersempit ruang lingkup sasaran yaitu dalam wilayah setingkat RW, dusun atau setara yang memiliki kriteria tertentu. Penelitian ini didasari oleh pencanangan Kampung Keluarga Berencana di Kabupaten Kuningan. Tujuan penelitian ini adalah untuk mengetahui gambaran implementasi program dan kendala pelaksanaan kegiatan Kampung KB.

Jenis penelitian ini adalah mix-methode yaitu studi kuantitatif dan kualitatif. Populasi penelitian adalah cakupan penggunaan Alat Kontrasepsi pada setiap Kecamatan/Desa yang memiliki Kampung KB di wilayah Kabupaten Kuningan. Sampel dalam penelitian ini adalah cakupan penggunaan Alat Kontrasepsi yang lengkap data-datanya pada setiap Kecamatan/Desa yang memiliki Kampung KB di wilayah Kabupaten Kuningan. Cara pengambilan sampel dalam penelitian ini adalah dengan yaitu total sampling. Variabel dalam penelitian ini adalah jumlah pengguna kontrasepsi sebelum dan sesudah menjadi kampung KB. Analisis data yang dilakukan yaitu analisis univariat dan analisis bivariat, uji yang digunakan yaitu dengan beda $T$ test berpasangan.

Hasil penelitian menunjukkan bahwa implementasi program Kampung KB di Kabupaten Kuningan secara umum berjalan dengan baik, hal ini dilihat dari terjadinya peningkatan akseptor KB antara sebelum dan sesudah ditetapkan sebagai Kampung KB yaitu dari 5.244 akseptor menjadi 5.519 akseptor. Kemudian, beberapa kegiatan Program KB sebagian besar telah dilakukan seperti penyuluhan, pembentukan Pusat Informasi dan Konseling Remaja, Bina Keluarga dan UPPKS. Hanya saja dari penelitian kualitatif ditemukan beberapa kendala yang terjadi seperti kurangnya antusias dan pemahaman dari masyarakat dan kurangnya kerjasama antar SDM yang menjalankannya.

Kesimpulan dari penelitian ini terdapat peningkatan akseptor $\mathrm{KB}$ antara sebelum dan sesudah ditetapkan sebagai Kampung KB di wilayah Kabupaten Kuningan. Saran kepada Pemerintah Daerah agar membantu dalam merealisasikan wilayah/desa yang belum membentuk Kampung KB.
\end{abstract}

Kata Kunci: Implementasi Kampung KB

Latar Belakang

OPEn 2 Access
Jumlah penduduk yang terus meningkat merupakan masalah besar bagi negara di dunia khususnya negara

E-ISSN 2623-1204 P-ISSN 2252-9462 |78 
JURNAL ILMU KESEHATAN BHAKTI HUSADA:

HeALTH SCIENCES JOURNAL, Vol. 09 No. 02, DESEMBER 2018

DOI: https://doi.org/10.34305/jikbh.v9i2.64

berkembang. Jumlah penduduk di Indonesia terus mengalami peningkatan pada setiap tahunnya. Indonesia merupakan negara dengan jumlah penduduk terbanyak keempat di dunia. Berdasarkan data yang dipublikasikan oleh Badan Pusat Statistik (BPS) (2017) bahwa jumlah penduduk Indonesia adalah pada tahun 2016 sebanyak 258.704.900 jiwa. Angka tersebut lebih tinggi sekitar $8,5 \%$ atau bertambah sebanyak 20.186.200 jiwa dibandingkan dengan tahun 2015 yang berjumlah 238.518 .800 jiwa.

Pertumbuhan penduduk yang tinggi akan menghambat laju pembangunan di berbagai bidang, oleh karena itu upaya mengatasi permasalahan ledakan penduduk tersebut, pemerintah Indonesia telah menerapkan program Keluarga Berencana (KB) yang bertujuan untuk mengendalikan pertumbuhan jumlah penduduk di Indonesia. Berdasarkan Undang-undang Nomor 52 tahun 2009 tentang Perkembangan Kependudukan dan Pembangunan Keluarga sebagai dasar pelaksanaan Program Kependudukan dan Keluarga Berencana menekan kewenangan Badan Kependudukan dan Keluarga Berencana Nasional untuk tidak memfokuskan pada masalah pengendalian penduduk saja, namun masalah Pembangunan Keluarga Berencana.

Berdasarkan data dari Badan Pusat Statistik (2017), Provinsi Jawa Barat menjadi provinsi dengan kepadatan penduduk paling tinggi di Indonesia yaitu dengan jumlah penduduk di Jawa Barat pada tahun 2017 mencapai 48 juta jiwa atau 18,34 persen dari total populasi Indonesia. Pergerakan laju pertumbuhan penduduk di Jawa Barat yang terus meningkat dapat dikendalikan dengan adanya program Keluarga Berencana. Salah satu strategi yang dapat dilakukan adalah dengan penerapan model Kampung KB. Melalui wadah Kampung $\mathrm{KB}$ ini nantinya diharapkan pelaksanaan program BKKBN dan program-program pembangunan lainnya dapat berjalan secara terpadu dan

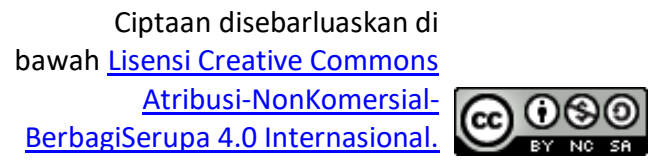

bersamaan. Hal ini sesuai dengan amanat yang tertuang dalam Agenda Prioritas Pembangunan periode 2015-2019, terutama agenda prioritas ke-3 yaitu memulai pembangunan dari pinggiran dengan memperkuat daerah-daerah dan desa dalam kerangka negara kesatuan.

Oleh karena itu, cukup beralasan apabila pembangunan kependudukan dimulai dari wilayah-wilayah pinggiran yaitu kampung, karena kampung merupakan cikal bakal terbentuknya desa, dan apabila pembangunan pada seluruh kampung maju, maka desapun akan maju, apabila seluruh desa maju maka sudah barang tentu negarapun akan menjadi maju.

Salah satu kabupaten di Provinsi Jawa Barat adalah Kabupaten Kuningan. Kabupaten Kuningan merupakan salah satu kabupaten yang mengalami perkembangan jumlah penduduk setiap tahunnya. Berdasarkan data dari Badan Statistik Kabupaten Kuningan, jumlah penduduk Kabupaten Kuningan berdasarkan proyeksi penduduk tahun 2013 tercatat 1.036.494 jiwa hingga pada tahun 2017 jumlah penduduk mencapai 1.068.201 jiwa. Dengan demikian dalam kurun waktu tersebut mengalami peningkatan sebesar 31.707 jiwa.

Hasil penelitian oleh Ariani tahun tahun 2018 di Kabupaten Deli Serdang menunjukan bahwa implementasi Program Kampung KB belum berjalan dengan baik hal ini dilihat dari pelaksanaan program ini yang tidak berjalan lagi serta banyak kekurangan dari berbagai indikator diantaranya sumber daya, hubungan antar organisasi, dan disposisi implementor (Ariani, 2018). Sedangkan penelitian yang dilakukan oleh Nosa dan Sri pada tahun 2016 di Kabupaten Sidoarjo menunjukkan hasil penelitian implementasi kampung KB berjalan baik. Hanya saja ada salah satu kegiatan yang belum terlaksana, yaitu Pusat Informasi Konseling Remaja (PIK) Remaja (Nosa dan Sri, 2016). Dan belum dilakukannya analisis implementasi 
JURNAL ILMU KESEHATAN BHAKTI HUSADA:

HeAlth SCIENCES JouRnal, Vol. 09 No. 02, DeSEMBER 2018

DOI: https://doi.org/10.34305/jikbh.v9i2.64

Program Kampung KB di Kabupaten Kuningan maka tidak diketahui hasil dari program Kampung KB. Oleh karena itu, dalam penelitian kali ini peneliti ingin mengetahui gambaran implementasi program Kampung KB di Kabupaten Kuningan tahun 2018.

\section{Tujuan Penelitian}

Tujuan secara umum penelitian ini adalah untuk mengetahui implementasi Kampung KB Kabupaten Kuningan tahun 2018 dengan pendekatan studi kuantitatif dan kualitatif. Sedangkan tujuan khusus penelitian ini adalah untuk mengetahui gambaran implementasi program dan kendala pelaksanaan kegiatan kampung KB.

\section{Metode Penelitian}

Jenis penelitian ini adalah mixmethode yaitu studi kuantitatif dan kualitatif. Populasi penelitian adalah cakupan pengunaan alat kontrasepsi pada setiap Kecamatan/Desa yang memiliki Kampung KB di wilayah Kabupaten Kuningan. Sampel dalam penelitian ini adalah cakupan pengunaan Alat Kontrasepsi yang lengkap

data-datanya pada setiap Kecamatan/Desa yang memiliki Kampung KB di wilayah Kabupaten Kuningan Jawa Barat tahun 2017 sebanyak 33 kampung KB. Cara pengambilan sampel dalam penelitian ini dengan melakukan pemilihan tidak berdasarkan peluang (non-probability sampling) yaitu total sampling. Lokasi penelitian adalah di semua Kampung yang telah ditetapkan menjadi Kampung KB di wilayah Kabupaten Kuningan. Penelitian ini telah dilakukan selama 8 bulan, dimulai dari bulan Februari 2018 - September 2018. Variabel dalam penelitian ini adalah jumlah pengguna kontrasepsi sebelum dan sesudah menjadi kampung KB. Pengumpulan data menggunakan metode kuantitatif dan data yang dikumpulkan yaitu data primer dari Petugas Lapangan KB (PLKB) dan data sekunder diambil dari Desa dan Dinas PPKB Kabupaten Kuningan. Analisis data yang dilakukan yaitu analisis univariat dan analisis bivariat, uji yang digunakan yaitu dengan beda $T$ test berpasangan, dengan software yang digunakan yaitu STATA versi 12

\section{Hasil}

\section{Studi Kuantitatif}

Berdasarkan hasil analisis univariat, didapatkan data sebagai berikut :

Tabel 1. Hasil Analisis Univariat

\begin{tabular}{lcc}
\hline Variabel & Frekuensi & Presentase $(\%)$ \\
\hline Penyuluhan KB & & 57,6 \\
Ya & 19 & 42,4 \\
Tidak & 14 & 72,7 \\
Pendewasaan Usia Perkawinan & & 27,3 \\
Ya & 24 & 75,8 \\
Tidak & 9 & 24,2 \\
Bina Keluarga & & 25 \\
Ya & 8 & 25 \\
Tidak & 8 &
\end{tabular}

Pusat Informasi Konseling Remaja 
JURNAL ILMU KESEHATAN BHAKTI HUSADA:

HEALTH SCIENCES JOURNAL, Vol. 09 No. 02, DESEMBER 2018

DOI: https://doi.org/10.34305/jikbh.v9i2.64

Ya

Tidak

Usaha Peningkatan Pendapatan Keluarga Sejahtera (UPPKS)

Ya

Tidak

Total

Berdasarkan tabel 1 didapatkan bahwa kampung KB melaksanakan aktivitas penyuluhan tentang penggunaan kontrasepsi sebanyak $57,6 \%$ dan masih terdapat $42,4 \%$ belum melakukan. Program pendewasaan usia perkawinan telah dilakukan oleh kampung KB sebanyak $72 \%$, dan sebanyak
Ciptaan disebarluaskan di bawah Lisensi Creative Commons

Atribusi-NonKomersialBerbagiSerupa 4.0 Internasional.
25

8

22

11
75,8

24,2

66,7

33,3

$33 \quad 100,0$

75\% kampung KB telah melaksanakan Program Bina Keluarga, Baik Bina Keluarga Balita maupun Bina Keluarga Lansia. Sebanyak $75,8 \%$ kampung KB telah membentuk Pusat Informasi dan Konseling Remaja (PIK-R) dan sebanyak 66,7\% telah melaksanakan program UPPKS.

Tabel 2. Perubahan Cakupan Penggunaan Alat Kontrasepsi sebelum dan sesudah ditetapkan sebagai Kampung KB

\begin{tabular}{lccc}
\hline Akseptor KB & Sebelum & Sesudah & Kenaikan \\
\hline Jumlah & 5.244 & 5.519 & $275(4.9 \%)$ \\
Rata-rata & 158,9 & 167,2 & \\
\hline
\end{tabular}

Berdasarkan tabel 2 didapatkan hasil bahwa, cakupan penggunaan alat kontrasepsi sebelum ditetapkan sebagai kampung KB sebanyak 5.244 akseptor dengan rerata 158,9 dan setelah ditetapkan menjadi Kampung KB menjadi 5.519 akseptor dengan rerata 167,2, dengan demikian kenaikannya sebanyak 275 akseptor $(4,9 \%)$ pada tahun 2017.

\section{Studi Kualitatif}

Berikut hasil wawancara dengan Petugas KB di Kecamatan Subang

"Narasumber:

Pak bagaimana di kecamatan Subang apakah sudah terbentuk Kampung KB?

Responden:

Sudah neng

Narasumber :

Tanggal ditetapkannya kapan pak? Terus bagaimana kegiatan Kampung KB itu sendiri apakah berjalan dengan lancar dan secara rutin?

Responden :
Nah itu dia neng jadi selama ini terdapat beberapa kendala yaitu karena pemberdayaan kurang, pemahaman masyarakat yang kurang, kurangnya antusias masyarakat, dan kurangnya kerjasama antar SDM, sebetulnya sosialisasi sudah dilakukan dan mulai berjalan tetapi masyarakatnya yang kurang faham jadi macet. Bilang kepada pihak yang meneliti tentang Kampung $K B$ bagaimana caranya agar masyarakat berdaya? Bagaimana teknisnya ? jangan sampai dengan adanya ini Desa Subang terkenalnya tidak melaksanakan kegiatan, kami sudah mengupayakan tetapi kembali lagi ke pemahaman masyarakat yang kurang, dan kurangnya kesadaran masyarakat"

Berikut hasil wawancara dengan Petugas KB di Kecamatan Ciawigebang "Kecamaatan Ciawigebang ada dua desa yang direncanakan untuk Kampung KB tetapi yang sudah dibentuk dan berjalan baru desa Ciawilor dan rencananya tahun

E-ISSN 2623-1204 P-ISSN 2252-9462 | 81 
JURNAL ILMU KESEHATAN BHAKTI HUSADA:

HeALTH SCIENCES JOURNAL, Vol. 09 No. 02, DESEMBER 2018

DOI: https://doi.org/10.34305/jikbh.v9i2.64
Ciptaan disebarluaskan di

bawah Lisensi Creative Commons

Atribusi-NonKomersial-

BerbagiSerupa 4.0 Internasional. depan akan mulai berjalan untuk desa Pamijahan".

Berikut hasil wawancara dengan Petugas KB di Kecamatan Japara "Kecamatan Japara ada dua Desa yang ada didaftar Kampung KB tetapi yang sudah berjalan baru Desa Dukuh Dalem saja dan Desa Japaranya belum, ketika dikonfirmasi ke pihak Desa Japara khususnya Kepala Desanya beliau mengatakan, sebenarnya untuk Desa Japara itu tidak pantas dijadikan sebagai Kampung KB karena memang disini kegiatan semacam posyandu, kegiatan remaja maupun lansia, sudah rutin dilaksanakan setiap bulannya, jadi yang sedang berjalan hanya di Desa Dukuh Dalem saja”.

Kesimpulannya, dari 35 Kampung KB yang terdaftar ada 32 Kampung KB yang sudah terbentuk dan mulai berjalan, adapun kendala-kendala setiap Desa sudah tercantum dalam tabel. Untuk tanggal ketetapan kampung KB tidak semua tercantum dalam SK ada sebagian yang tercantum hanya bulan dan tahunnya saja.

\section{Pembahasan}

Secara umum, tujuan dibentuknya Kampung KB adalah untuk meningkatkan kualitas hidup masyarakat di tingkat kampung atau setara melalui program kependudukan, keluarga berencana dan pembangunan keluarga serta pembangunan sektor terkait lainnya dalam rangka mewujudkan keluarga kecil berkualitas.

Berdasarkan hasil temuan diatas dapat dinyatakan bahwa tujuan umum Kampung KB di Kabupaten Kuningan telah tercapai. Hal ini terlihat dari meningkatnya jumlah pengguna KB (akseptor KB) sebelum dan sesudah ditetapkan sebagai Kampung KB yaitu meningkat sebesar $4,9 \%$, hal ini dikarenakan program kampung KB dengan kegiatan yang utama yang berkaitan langsung dengan peningkatan akseptor yaitu sosialisasi dan internalisasi kesehatan reproduksi dan sosialisasi pengaturan jarak kelahiran anak (3-5 tahun) dengan penggunaan metode kontrasepsi dalam bentuk penyuluhan KB. Penyuluhan bertujuan untuk meningkatkan pengetahuan, sikap dan akhirnya merubah perilaku masyarakat termasuk perilaku penggunaan kontrasepsi (Mbizvo, M. and Adamchak, 1991). Kegiatan penyuluhan sebagai bentuk sosialisasi tentang penggunakan kontrasepsi di Kampung KB Kabupaten Kuningan sebagian besar melaksanakan (57,6\%). Penyuluhan berhubungan dengan peningkatan pengetahuan, hasil ini sejalan dengan penelitian Setiawati (2017) menunjukan terdapat pengaruh penyuluhan dan konseling terhadap pengetahuan tentang KB di Puskesmas Plus Bara-Baraya dan di klinik Wirahusada Medical center Makassar (Setiawati and Irmawati, 2017). Dan juga terlihat dari beberapa program/kegiatan yang sebagian besar berhasil dilaksanakan seperti Program Penyuluhan KB, Program Pendewasaan Usia Perkawinan, Program Bina Keluarga dan terbentuknya Pusat Informasi dan Konseling Remaja.

Sesuai dengan (BKKBN,2015) keluarga berencana merupakan upaya untuk mewujudkan keluarga yang berkualitas melalui promosi, perlindungan, dan bantuan dalam mewujudkan hak-hak reproduksi serta penyelenggaraan pelayanan, pengaturan, dan dukungan yang diperlukan untuk membentuk keluarga dengan usia kawin yang ideal, mengatur jumlah, jarak dan usia ideal melahirkan anak, mengatur kehamilan dan membina ketahanan serta kesejahteraan anak. Berdasarkan pengertian di atas dapat diketahui bahwa ciri dari keluarga yang berkualitas diantaranya adalah memiki jumlah anak yang ideal, mengatur jumlah jarak dan usia melahirkan anak. Salah satu cara yang dapat dilakukan untuk mewujudkan keluarga yang berkualitas adalah dengan menjadi pengguna $\mathrm{KB}$.

Beberapa tujuan khusus dari Kampung KB adalah meningkatkan kesadaran masyarakat tentang pembangunan

E-ISSN 2623-1204 P-ISSN 2252-9462 | 82 
JURNAL ILMU KESEHATAN BHAKTI HUSADA:

HEALTH SCIENCES JOURNAL, Vol. 09 No. 02, DESEMBER 2018

DOI: https://doi.org/10.34305/jikbh.v9i2.64

berwawasan kependudukan. Hasil penelitian menunjukan bahwa dari 35 Kampung KB yang terdaftar, terdapat 32 Kampung $\mathrm{KB}$ yang sudah terbentuk dan mulai berjalan. Hal ini menunjukkan bahwa partisipasi masyarakat dalam mengikuti Program Kampung KB di Kabupaten Kuningan tergolong tinggi. Ini merupakan indikasi meningkatnya kesadaran masyarakat mengenai pembangunan berwawasan kependudukan yang salah satunya adalah program KB.

Tujuan khusus lainnya dari Program Kampung KB adalah meningkatkan Ketahanan Keluarga melalui Bina Keluarga Balita (BKB), Bina Keluarga Remaja (BKR), Bina Keluarga Lansia (BKL) serta Pusat Informasi dan Konseling (PIK) Remaja. Berdasarkan hasil penelitian Program Kampung KB yakni Bina Keluarga Baik, Bina Keluarga Balita, dan Bila Keluarga Lansia telah dibentuk dan dilaksanakan hingga saat ini yaitu sebanyak 75\%. Dan sebanyak 75,8\% kampung KB telah membentuk Pusat Informasi dan Konseling Remaja (PIK-R) dan sebanyak $66,7 \%$ telah melaksanakan program UPPKS

\section{Kesimpulan dan Saran}

Berdasarkan hasil penelitian dapat disimpulkan bahwa implementasi program Kampung KB di Kabupaten Kuningan telah dilaksanakan dengan optimal, hal ini dilihat dari terjadinya peningkatan akseptor $\mathrm{KB}$ antara sebelum dan sesudah ditetapkan sebagai Kampung KB di wilayah Kabupaten Kuningan.

Saran kepada Pemerintah Daerah agar membantu dalam merealisasikan wilayah/desa yang belum membentuk Kampung KB.

\section{Daftar Referensi}

Irawani, T. N. (2018) Hubungan antara sosialisasi program keluarga berencana dengan sikap masyarakat

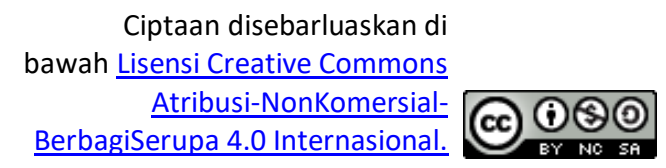

untuk ber-KB. Available at: http://hdl.handle.net/123456789/15227.

Mbizvo, M. and Adamchak, D. (1991)

'Family Planning Knowled ge, Attitudes, and Practices of Men in Zimbabwe', Studies in Family Planning, 22(1), pp. 31-38.

Mutobiah and Rahayu, S. (2016) 'Hubungan Pengetahuan Akseptor Wanita Dengan Penggunaan Alat Kontrasepsi IUD Di Desa Ngadiwarno Kecamatan Sukorejo Kabupaten Kendal', Journal Of Nursing And Health, 1(2), pp. 26-30.

Octaviani, A. (2016) Efektifitas Kebijakan

Kampung Keluarga Berencana

Terhadap Penerimaan Konsep

Keluarga Berencana (Studi Kasus

Faktor Institusional dan Faktor Sosial di Kecamatan Jeruklegi Kabupaten Cilacap). Universitas Sebelas Maret.

Patah (2016) No Title, BPPSDMD Jawa Tengah.

Rey, M. F. (2017) Hubungan Karakteristik Ibu dengan Pemilihan Metode Kontrasepsi Jangka Panjang (MKJP) dan Non MKJP di Kampung KB Bangau Putih Kota Padang. Universitas Andalas. Available at: http://scholar.unand.ac.id/20929/.

Rifki, N. M. and Setyawan, S. (2018) Sosialisasi Program Kampung Keluarga Berencana (kampung kb) Di Kelurahan Pucang Sawit. Universitas Muhammadiyah Surakarta. Available at:

http://eprints.ums.ac.id/65298/3/Bismil lah daftar Sidang rif.pdf.

Saleh, A. et al. (2012) 'No Title', 10(2), pp. 43-64.

Setiawati, D. and Irmawati, I. (2017) 'Pengaruh Penyuluhan dan Konseling terhadap Peranan Gender terhadap Pemilihan Metode Kontrasepsi Pasangan suami-istri dan Pengaruhnya Terhadap Tingkat Kepuasan Seksual, Jurnal Kesehatan, 1(2), pp. 41-50. Available at: http://journal.uin- 
JURNAL ILMU KESEHATAN BHAKTI HUSADA:

HeALTH SCIENCES JOURNAL, Vol. 09 No. 02, DESEMBER 2018

DOI: https://doi.org/10.34305/jikbh.v9i2.64

alauddin.ac.id/index.php/kesehatan/arti cle/view/4382.

Setiawati, E. (2017) 'Persepsi Masyarakat Terhadap Program Kampung Keluarga Berencana Di Kelurahan Pantoloan Boya Kecamatan Tawaeli, GeoTadulako, 5(1). Available at: http://jurnal.untad.ac.id/jurnal/index.ph p/GeoTadulako/article/view/9003.

Surapaty, C. (2016) No Title, BKKBN.

Sutanto (2015) Kampung KB , Revolusi Program Keluarga Berencana Berbasis Masyarakat, BKKBN Sulawesi Selatan.

Wahyuningsih, A. and Iita, M. Z. (2018) 'Kajian Karakteristik Kampung Keluarga Berencana (KB) di Desa Mojoranu Kecamatan Sooko Kabupaten Mojokerto', Swara Bhumi, 5(7). Available at: http://jurnalmahasiswa.unesa.ac.id/inde x.php/swara-

bhumi/article/view/24980/22887.

Irawani, T. N. (2018) Hubungan antara sosialisasi program keluarga berencana dengan sikap masyarakat untuk ber-KB. Available at: http://hdl.handle.net/123456789/15227.

Mbizvo, M. and Adamchak, D. (1991) 'Family Planning Knowledge, Attitudes, and Practices of Men in Zimbabwe, Studies in Family Planning, 22(1), pp. 31-38.

Mutobiah and Rahayu, S. (2016) 'Hubungan Pengetahuan Akseptor Wanita Dengan Penggunaan Alat Kontrasepsi IUD Di Desa Ngadiwarno Kecamatan Sukorejo Kabupaten Kendal', Journal Of Nursing And Health, 1(2), pp. 26-30.

Octaviani, A. (2016) Efektifitas Kebijakan Kampung Keluarga Berencana Terhadap Penerimaan Konsep Keluarga Berencana (Studi Kasus Faktor Institusional dan Faktor Sosial di Kecamatan Jeruklegi Kabupaten Cilacap). Universitas Sebelas Maret.

Patah (2016) No Title, BPPSDMD Jawa Tengah.

\section{Ciptaan disebarluaskan di \\ bawah Lisensi Creative Commons \\ Atribusi-NonKomersial- BerbagiSerupa 4.0 Internasional.}

Rey, M. F. (2017) Hubungan Karakteristik Ibu dengan Pemilihan Metode Kontrasepsi Jangka Panjang (MKJP) dan Non MKJP di Kampung KB Bangau Putih Kota Padang. Universitas Andalas. Available at: http://scholar.unand.ac.id/20929/.

Rifki, N. M. and Setyawan, S. (2018) Sosialisasi Program Kampung Keluarga Berencana (kampung kb) Di Kelurahan Pucang Sawit. Universitas Muhammadiyah Surakarta. Available at:

http://eprints.ums.ac.id/65298/3/Bismil lah daftar Sidang rif.pdf.

Saleh, A. et al. (2012) 'No Title', 10(2), pp. 43-64.

Setiawati, D. and Irmawati, I. (2017) 'Pengaruh Penyuluhan dan Konseling terhadap Peranan Gender terhadap Pemilihan Metode Kontrasepsi Pasangan suami-istri dan Pengaruhnya Terhadap Tingkat Kepuasan Seksual', Jurnal Kesehatan, 1(2), pp. 41-50. Available at: http://journal.uinalauddin.ac.id/index.php/kesehatan/arti cle/view/4382.

Setiawati, E. (2017) 'Persepsi Masyarakat Terhadap Program Kampung Keluarga Berencana Di Kelurahan Pantoloan Boya Kecamatan Tawaeli, GeoTadulako, 5(1). Available at: http://jurnal.untad.ac.id/jurnal/index.ph p/GeoTadulako/article/view/9003.

Surapaty, C. (2016) No Title, BKKBN.

Sutanto (2015) Kampung KB , Revolusi Program Keluarga Berencana Berbasis Masyarakat, BKKBN Sulawesi Selatan.

Wahyuningsih, A. and Iita, M. Z. (2018) 'Kajian Karakteristik Kampung Keluarga Berencana (KB) di Desa Mojoranu Kecamatan Sooko Kabupaten Mojokerto', Swara Bhumi, 5(7). Available at: http://jurnalmahasiswa.unesa.ac.id/inde x.php/swarabhumi/article/view/24980/22887. 
JURNAL ILMU KESEHATAN BHAKTI HUSADA:

HeAlth SCIENCES JouRnal, Vol. 09 No. 02, DeSEMBER 2018

DOI: https://doi.org/10.34305/jikbh.v9i2.64
Ciptaan disebarluaskan di bawah Lisensi Creative Commons

Atribusi-NonKomersialBerbagiSerupa 4.0 Internasional. 